Revista Iberoamericana, Vol. LXXVIII, Núms. 238-239, Enero-Junio 2012, 73-89

\title{
VIRTUALIDADES DISTÓPICAS EN LA FICCIÓN ANALÓGICA: LA INVENCIÓN DE MOREL, DE ADOLFO BIOY CASARES
}

\author{
POR \\ Teresa López Pellisa \\ Universidad Autónoma de Barcelona
}

\begin{abstract}
¿Lescuesta admitirun sistema de reproducción de vida, tan mecánico y artificial? Recuerden que en nuestra incapacidad de ver, los movimientos del prestidigitador se convierten en magia.
\end{abstract}

La invención de Morel, Bioy Casares

Con La invención de Morel (1940), el escritor de ciencia-ficción y literatura fantástica Adolfo Bioy Casares (1914-1999) nos presenta una distopía científica al tiempo que Morel -el científico protagonista de la ficción- simula su tecnoutopía: la inmortalidad junto a su amada virtual Faustine. La máquina de Morel genera una suerte de realidad virtual, basada en la fusión de tecnología cinematográfica y holográfica, inmersa en un atroz eterno retorno que reproduce una semana de vacaciones en la isla. Las lecturas multiformes que permite este artefacto literario incluyen el análisis de la nueva ecología mediática de principios de siglo xx en Argentina, y también del siglo xxI, donde el impacto de las nuevas tecnologías informáticas y los medios de representación han transformado nuestro espacio simbólico. A continuación presentamos una lectura cibercultural de la novela y algunos de los discursos intermediales que la articulan.

\section{FOTO(FANTASMA)GRAFÍA EN MOVIMIENTO}

“¿Quién no desconfiaría de una persona que dijera: Yo y mis compañeros somos apariencias, somos una nueva clase de fotografías?” (160), nos interroga nuestro escritor y fugitivo protagonista de La invención de Morel. A finales del siglo xix la fotografía se había insertado en el campo simbólico rioplatense y la literatura se hacía eco de las posibilidades sugestivas de la reproducción mecánica, como muestra la influencia de la tecnología del fonógrafo, la fotografía y el cinematógrafo en algunos relatos de Leopoldo Lugones, Horacio Quiroga, Rubén Darío y Eduardo Ladislao Holmberg, entre 
otros. ${ }^{1}$ El científico Morel investiga sobre las capacidades tecnológicas de los medios de comunicación y considera que la radiotelefonía, el fonógrafo y el teléfono suprimen las ausencias espaciales para el sentido del oído. La televisión, el cine y la fotografía, por su parte, eliminan la distancia para el sentido de la vista. Concluye que las posibilidades para contrarrestar el resto de los sentidos todavía no se han desarrollado, así que pretende congregar todos los sentidos en sus reproducciones artificiales creando un nuevo tipo de fotografía: "Me puse a buscar ondas y vibraciones inalcanzadas, a idear instrumentos para captarlas y transmitirlas. Obtuve, con relativa facilidad, las sensaciones olfativas; las térmicas y las táctiles propiamente dichas requirieron toda mi perseverancia” (155). El artefacto tecnológico que asedia la isla es descrito como un proyector cinematográfico, aunque su resultado sea lo que hoy conocemos por realidad virtual. Noël Burch, en El tragaluz infinito, explica cómo el propio Edison pretendía conquistar la naturaleza a través de sus reproductores de imágenes para triunfar sobre la muerte y consideraba que "El estereoscopio da la sensación de relieve a los objetos. El fenakistiscopio da la del movimiento. El esterefantascopio o bioscopio da, a un tiempo, como indica su nombre, la sensación de relieve y del movimiento, o da la sensación de la vida” (22). Burch ejemplifica con varios artículos de la época esta idea metafísica y trascendental que parecía emanar del celuloide y que puede verse perfectamente reflejada en la novela de Bioy Casares. George Demenÿ (1850-1917) comentaba:

Cuántas personas serían felices si pudieran volver a ver los rasgos de alguien que hoy ha desaparecido. El futuro reemplazará a la fotografía inmóvil, congelada, por el retrato animado, al que se podrá, con una vuelta de rueda, devolver la vida.

Se conservará la expresión de la fisonomía como se conserva la voz en un fonógrafo. Incluso se podrá añadir este último al fonoscopio para complementar la ilusión. A partir de ahora ya no hará falta analizar más, se hará revivir. (Citado por Burch 43)

La novela que nos ocupa se articula en torno a la construcción de un deseo y su imposibilidad. El erudito tecnólogo había perdido la esperanza de enamorar a Faustine y construyó la máquina para "dar perpetua realidad a mi [su] fantasía sentimental" (153). La motivación sexual del científico y su obsesión erótica hacia Faustine nos muestra unas estructuras discursivas perversas, ya que su acción se configura en torno a una tecnología que al grabar una imagen mata los originales. Como indica el teórico posmoderno Baudrillard, "la era de la simulación se abre, pues, con la liquidación de todos los referentes" (11). Ya no podemos utilizar términos como el de representación o imitación, sino el de suplantación, y tal y como postula el filósofo francés, podemos afirmar que en La invención de Morel "lo real no tendrá nunca más ocasión de producirse

1 Para ampliar la información sobre la repercusión de la fotografía en la sociedad y la literatura rioplatense remitimos al trabajo de Valeria de los Ríos.

$\begin{array}{lllll}\text { ISSN 0034-9631 (Impreso) } & \text { ISSN 2154-4794 (Electrónico) }\end{array}$ 
-tal es la función vital del modelo en un sistema de muerte” (11). Sistema que implanta Mor(t)el, en la misteriosa idílica isla del Pacífico, sobre sus amigos y sobre el ecosistema que habitan.

La recreación de este tipo de simulaciones sentimentales a través de la tecnología ha sido un motivo recurrente en la literatura de ciencia-ficción. Desde la siniestra Olimpia de Hoffman (1817), a La Eva futura (1879), de Villiers de l’Isle Adam, Horacio Kaliban o los autómatas (1879), de Eduardo L. Holmberg, El castillo de los Cárpatos (1892), de Julio Verne y Avatar (1856), de Théophile Gautier. Aunque indudablemente podemos considerar como los intertextos más explícitos, en relación a la novela de Adolfo Bioy Casares, “El vampiro” de Horacio Quiroga (1935)² y XYZ (1935), de Clemente Palma. Baudrillard considera que "simular es fingir tener lo que no [se] tiene" (12) y en eso consisten las relaciones virtuoamorosas que mantienen los personajes masculinos de estas ficciones con sus cibergalateas.

Thomas Alva Edison (1847-1931) -el brujo de Menlo Park- es un referente tanto en la historia de la ciencia y la tecnología por sus trabajos en fotografía e inventos como el fonógrafo (1877) o el kinetoskopio (1891), como en la literatura de ciencia-ficción. ${ }^{3}$ El personaje real estaba interesado en las potencialidades metafísicas de sus inventos, acudía a las reuniones de la Sociedad Teosófica en Nueva York y visitaba a la maestra teosófica Helena Petrovna Blavatsky (1831-1891). En los años veinte se publicaron varios artículos sobre sus trabajos en una especie de teléfono cuyo funcionamiento con tecnología de ondas electromagnéticas le permitiría comunicarse con el más allá. A pesar de los desmentidos por parte de alguno de sus biógrafos, Martin Gardner cita el artículo “The Diary and Sundry Observations of Thomas A. Edison” aparecido en el Philosophical Library de Dagobert Rune (1948), donde el inventor del fonógrafo confiesa que:

He estado trabajando durante algún tiempo en la construcción de un aparato para ver si es posible que las personalidades que han dejado este mundo se comuniquen con nosotros. Si alguna vez se consigue tal cosa, no se conseguirá por medios ocultistas, misteriosos o extraños, como los que utilizan los llamados médiums, sino por métodos científicos. (266)

Villiers de l'Isle Adam convirtió a Edison en el protagonista alquimista prometeico capaz de engendrar ginoides sumisas, a base de metal, pero con un motor espectral que

2 Existe una versión anterior de “El vampiro” de Quiroga aunque apareció publicado en 1935 en Más Allá, el original es de 1927.

3 John Clute y Peter Nichols en La Enciclopedia de la Ciencia-Ficción hacen referencia a la influencia de Thomas Alva Edison en la literatura de ciencia-ficción de finales del siglo xix y principios del xx (368370).

\footnotetext{
Revista Iberoamericana, Vol. LXXVIII, Núms. 238-239, Enero-Junio 2012, 73-89 ISSN 0034-9631 (Impreso) ISSN 2154-4794 (Electrónico)
} 
hacía convivir al fonógrafo con la aleación y lo sagrado en una Hadalay que permitía decirle a la Naturaleza: “iAdiós, presunta Realidad, vieja engañadora! Os brindo lo ARTIFICIAL y sus incitaciones desconocidas. El peligro reside en quedar dominado por ellas” (118). El fabricante de autómatas de Eduardo L. Holmberg se inspira en el brujo de Menlo Park para crear sus criaturas. Estos automatismos antropomórficos son simulaciones exactas de personas. Baum, o Fritz, puebla el mundo de Horacios Kalibanges cuya artificialidad es imperceptible y considera que el ser humano no es más que "¿una máquina cuyos exquisitos resortes se mueven en virtud de impulsos mil y mil veces transformados?, ¿qué es el alma, sino el conjunto de esas funciones mecánicas?” (12), recogiendo la tradición de René Descartes en El tratado del hombre (1633), y Julien Offray de La Mettrie en El hombre máquina (1747).

El científico Orfanik, de El Castillo de los Cárpatos, de Verne, se basa en los trabajos de Edison sobre el fonógrafo y la electricidad para crear un artefacto que registra y proyecta la voz y la imagen de la cantante Stilla eternamente. En este caso, como en $\mathrm{La}$ invención de Morel y el "Retrato oval” de Edgar Allan Poe, la simulación succiona la vida y el alma del cuerpo expuesto, provocando la muerte del original. La retención de la imagen a través de los espejos y la proyección cuasi holográfica de la imagen femenina se reproducen en la obra de Bioy. En la novela Avatar, de Théophile Gautier, un doctor instruido en la India bajo la tutela de brahmanes y yoghis puede transmigrar el alma de un cuerpo a otro gracias a un aparato, cuya fuente de energía es el magnesio, y un ritual sagrado. En este caso, el joven Octavio de Saville está enamorado de la felizmente casada condesa Prascovia Labinska y decide traspasar su alma al cuerpo del marido de ella. Como en la mayoría de estas novelas, retar el orden establecido por Dios, o el universo, es penalizado y se paga con la muerte. El título de la novela hace referencia a la reencarnación de una deidad hindú, y en el ciberespacio se ha tomado prestada la palabra avatar para las múltiples reencarnaciones que experimentan los ciberusuarios al transmigrar de una de sus representaciones gráficas a otra. En la obra de Gautier la tecnoextracción del alma situada en la glándula pineal posibilita la transmigración de las almas entre los cuerpos como si se tratara del metaverso. ${ }^{4}$ Este motivo lo utiliza también Bioy Casares en su satírica novela Dormir al Sol con el objetivo, nuevamente, de conseguir a una mujer.

En 1895 Ferdinand Braum inventaba los rayos catódicos mencionados por Horacio Quiroga en "El vampiro" (1935), propiciando la tecnología que se utilizaría para los monitores de los visiocascos empleados en las inmersiones de realidad virtual de los años

4 El término metaverso fue acuñado por Neal Stephenson en la novela de ciencia-ficción ciberpunk Snow Crash (1992) para referirse al ciberespacio 3D en el que interactúan los personajes del texto. La ficción también ha engendrado el concepto de ciberespacio en la novela ciberpunk Neuromante (1984), de William Gibson, para hacer referencia a un no-espacio en el que interactúan seres humanos e inteligencias artificiales en la red.

$\begin{array}{lllll}\text { ISSN 0034-9631 (Impreso) } & \text { ISSN 2154-4794 (Electrónico) }\end{array}$ 
sesenta. En este relato, el excéntrico Rosales trabaja en la retención de los movimientos de los instantes fotográficos de una actriz en una película, a través de la proyección de rayos N1 sobre el celuloide. De este modo logra un doble espectral surgido del haz de interferencias de la proyección -una pseudoholografía con autonomía de movimiento-, gracias a la convicción de que el cinematógrafo no sólo muestra la imagen de una actriz en movimiento, sino la fuerza de su alma:

¿Sabe usted lo que es la vida de una pintura, y en qué se diferencia un mal cuadro de otro? El retrato oval de Poe vivía, porque había sido pintado con "la vida misma". ¿Cree usted que sólo puede haber un galvánico remedo de vida en el semblante de la mujer que despierta, levanta e incendia la sala? ¿Cree usted que una simple ilusión fotográfica es capaz de engañar de ese modo el profundo sentido que de la realidad femenina posee un hombre? (Quiroga 60)

Rosales, como Morel y el Dr. XYZ, no crea vida, tan solo la reproduce, y de ahí que necesite "emisores vivos" (La invención 157).

En el caso de la novela XYZ (1934), del peruano Clemente Palma, el científico protagonista se adhiere explícitamente a los trabajos de Edison y a La Eva futura de Villiers de l'Isle Adam, así como a la amplia trayectoria de alquimistas medievales dedicados a la reproducción artificial del ser humano, como Alberto Magno (ca. 11931280) o Paracelso (1493-1541). Mr. Rolland Poé (Dr. XYZ) se centra en la tecnología cinematográfica para crear dobles de Hollywood inmortales. El invento del Dr. XYZ se centra en las filmaciones cinematográficas de actrices, perfeccionando las técnicas estereoscópicas hasta el punto de complementar las sensaciones visuales y auditivas del cine sonoro, con el tacto y el olfato. Utilizando la albúmina del huevo de tortuga y de gallina como materia prima para sus moldes, logra reproducir sus andromorfos a través de la proyección de radium sobre esta biotecnología. Sus réplicas cinematográficas viven cuatro meses, aunque él se ha propuesto ser el ave fénix de sus creaciones para que vivan eternamente al margen del tiempo y así "[...] se cumplirá el prodigio de una juventud virtualmente eterna, realizando el sueño de Fausto, que Mefistófeles cumplió con una parsimonia que la ciencia no tendrá. Vivirán mis andrógenos envueltos en el torbellino de la vida universal, pero desglosados de la curva del Tiempo” (Palma 34). El Dr. XYZ produce seres fílmicos, como el personaje-actor Jeff Daniels de La rosa púrpura del Cairo (1985), de Woody Allen, en cambio Morel crea un holofilm ${ }^{5}$ que incluye el tacto y el olfato, pero no se puede interactuar con sus imágenes virtuales. La

5 Hasta los años setenta no se crearon las primeras películas holográficas. Entre los investigadores más destacados en el campo de la cinematografía holográfica se encuentran Lloyd Cross y Víctor Komar. En los años cincuenta Hans Lube incluyó el sentido del olfato en un espectáculo cinematográfico con el dispositivo Smell-O-Vision y la primera película que reprodujo imágenes, sonido y olores fue Scent of Mystery (1960).

$\begin{array}{llllll}\text { ISSN 0034-9631 (Impreso) } & \text { ISSN 2154-4794 (Electrónico) }\end{array}$ 
máquina de Morel proyecta un cine wagneriano que bautizó como sensorama (feelies) Aldous Huxley en Un mundo feliz (1932).

El informático y teórico del hipertexto Theodor Nelson consideraba que la realidad virtual no era más que una rama de la cinematografía. Los avances en tecnología estereoscópica en la fotografía y el cinematógrafo, a finales del siglo XIX, llevaron a Raoul Grimoin a presentar el Cinéorama en la Exposición Universal de París de 1900, acercando así el cine 3D al gran público. En 1915 el Teatro Astor de Nueva York proyectó tres cortometrajes 3D de Hugh Ford y Edwin S. Porter y en 1936 Guido Brignone proyectaba el largometraje, 3D y sonoro, Nozze Vagabonde. El primer prototipo de realidad virtual, analógico, fue el Sensorama -como homenaje a Huxley- creado por Morton Heiling, en 1962, tras el impacto que le ocasionó ver Esto es Cinerama (1952) de Mark Todd. Heiling concibió su concepto The Experience Theater como una tecnología que sustituyera la clásica experiencia cinematográfica y simulara la vida:

Decidí inventar yo mismo el medio y concebí y patenté “El Teatro de la Experiencia”. Mi concepto ofrecía un modo de aprovechar toda la tecnología entonces disponible para crear una sala de cine en la que se dieran representaciones con una ilusión total de realidad. Me di cuenta de que para lograrlo, era necesario repartir la información sensorial global en varios componentes (la vista, los olores, el movimiento, el sonido) que debían integrarse. [...] también proporcionaba sensaciones de temperatura, de movimiento, de vibraciones y del viento en el cuerpo de los espectadores. Un componente clave del concepto era el asiento, que vibraba y se inclinaba. (Citado por Burdea y Coiffet 26-27)

Las imaginaciones razonadas, de Adolfo Bioy Casares, asumen la aparatología tecnológica de la época, junto a teorías científicas como las de Newton, Charles Darwin, Thomas Alva Edison, Francis Galton o John Dunne, para combinarlas con ciertos conceptos teosóficos que potencian su metafisificción virtual en textos como La invención de Morel o Plan de Evasión. El te(o)cnólogo Morel decidió erigirse en demiurgo de su mortal imagouniverso eterno: "Hubo, además, que perfeccionar los medios existentes. Los mejores resultados honraban a los fabricantes de discos de fonógrafo. Desde hace mucho era posible afirmar que ya no temíamos a la muerte, en cuanto a la voz” (155), y él se proponía perfeccionar las imágenes que se archivaban en la fotografía y el cine para no temerle a la muerte en cuanto al resto de los componentes del ser humano. Esta fe en que las nuevas tecnologías puedan aportar novedades metafísicas a nuestras vidas es una constante en la novela que analizamos ${ }^{6}$ y aparece en otros relatos de Bioy como "Los afanes" (1962). Morel cree que ya no se puede temer a la muerte gracias al fonógrafo, la fotografía y el cine, pero también considera que su invento va más allá:

6 Sobre la relación entre ciencia, tecnología y religión remitimos a los ensayos La religión de la tecnología de David Noble y La nueva ciudad de Dios de Andoni Alonso e Iñaki Arzoz.

$\begin{array}{lllll}\text { ISSN 0034-9631 (Impreso) } & \text { ISSN 2154-4794 (Electrónico) }\end{array}$ 
Estaba seguro de que mis simulacros de personas carecerían de conciencia de sí (como los personajes de una película cinematográfica). Tuve una sorpresa: después de mucho trabajo, al congregar esos datos armónicamente, me encontré con personas reconstituidas, [...] para nadie podrían distinguirse de las personas vivas (se ven como circulando en otro mundo, fortuitamente abordado por el nuestro). [...] Congregados los sentidos, surge el alma. Había que esperarla. Madeleine estaba para la vista, Madeleine estaba para el oído, Madeleine estaba para el sabor, Madeleine estaba para el olfato, Madeleine estaba para el tacto: Ya estaba Madeleine. (156-57)

La primera parte de la máquina de Morel capta las imágenes, la segunda las graba y la tercera las proyecta. Para Morel no hay duda acerca de la hipótesis del alma en estas creaciones artificiales, y se basa en los efectos que produce la máquina sobre las personas, animales y vegetales emisores: los desintegra. La materialidad del mundo virtual no comparte su composición con la del espacio real: "El espacio digital es un poderoso disolvente; todo, independientemente del tamaño, el material, el color, el estado, la función, sea un objeto o una actividad, todo lo diluye y lo convierte en ristras de ceros y unos" (Rodríguez de las Heras 15), y de este modo entiende Morel que la vida o el alma o la conciencia pasan del emisor al clon tridimensional. Este mundo hologramático paralelo al real está conformado por una inmaterialidad que le otorga un estatus imperecedero, pero supone la muerte del cuerpo real para lograr la inmortalidad del cuerpo virtual. El protagonista describe su proceso degenerativo tras la exposición a la máquina: "Pierdo la vista. El tacto se ha vuelto impracticable; se me cae la piel; las sensaciones son ambiguas, dolorosas; procuro evitarlas. Frente al biombo de espejos, supe que estoy lampiño, calvo, sin uñas [...]” (184). Ni la ilustración ni el positivismo han suprimido el estigma judeocristiano de Occidente, y el siglo xxI-2.0 continúa teniendo alma, aunque ahora se trate de un alma cibernética:

La inteligencia artificial (IA) hace una defensa muy elocuente de las posibilidades de la inmortalidad y la resurrección basada en las máquinas, y sus discípulos, los arquitectos de la realidad virtual y del ciberespacio, están exultantes ante sus expectativas de una omnipresencia de carácter divino y de perfección incorpórea. Los ingenieros genéticos se imaginan a sí mismos como participantes divinamente inspirados en una nueva creación. Todos estos pioneros tecnológicos albergan creencias profundamente asentadas que son variaciones de temas religiosos que nos son familiares. (Noble 17)

Las imágenes que reproduce el invento de Morel son holográficas ${ }^{7}$ y funcionan

7 La holografía fue inventada en 1948 por el premio Nobel en Física Dennis Gabor. Según Nicholas Negroponte "un holograma es una colección de todos los puntos de vista posibles en un solo plano de patrones de modulación de luz. Cuando se hace pasar la luz a través de este plano, o se refleja desde él, la escena se reconstruye ópticamente en el espacio” (149). La etimología proviene del griego holos-todo

\begin{tabular}{l} 
Revista Iberoamericana, Vol. LXXVIII, Núms. 238-239, Enero-Junio 2012, $73-89$ \\
\hline ISSN 0034-9631 (Impreso)
\end{tabular} 
de un modo analógico gracias a la activación de las máquinas por la fuerza hidráulica de las mareas. Los holocuerpos de la virtualidad moreliana vivirán "en esa fotografía, siempre” (153), inmortalmente y descorporalizados, ya que "sólo había que buscar la conservación de lo que interesa a la conciencia” (100). Y aunque se considera una herejía transformar el cuerpo, por estar fabricado a imagen y semejanza de Dios, parece que la ambigüedad de las escrituras sagradas muestra ciertos resquicios en los que se permite al ser humano forjarse la forma corporal que desee, poniendo en práctica las propuestas artísticas que performers como Orlan o Stelarc abanderan, partiendo de la premisa de que el cuerpo está obsoleto. Pico della Mirandola, en su discurso De la dignidad del hombre (1486), recoge las palabras de Yavé en el Génesis donde se muestra esta ambigüedad:

No te he hecho ni celeste ni terreno, ni mortal ni inmortal, con el fin de que tú, como árbitro y soberano artífice de ti mismo, te informases y plasmases en la obra que prefirieses. Podrás degenerar en los seres inferiores que son las bestias, podrás regenerarte, según tu ánimo, en las realidades superiores que son divinas.

"Más humanos QUE LOS HUMANOS”

El físico Frank Tipler, en La física de la inmortalidad, propone una metafísica derivada de los ordenadores. Considera que la teología no es más que una cosmología física basada en la idea de que la vida es inmortal, y demuestra sus postulados desde el materialismo científico y no desde la fe, describiendo el mecanismo físico a través del cual tiene lugar la resurrección universal sin la intervención de ningún fenómeno sobrenatural. Frank Tipler considera el alma humana como un programa ejecutado por un ordenador llamado cerebro. Para el científico, igual que para Marvin Minsky y Hans Moravec, " "el mecanismo físico responsable de la resurrección individual consiste en la simulación de todas y cada una de las personas fallecidas hace tiempo -junto con los mundos en que vivieron- en los ordenadores del futuro lejano" (47). ${ }^{9}$ Pero no se trataría tan sólo de una simulación, como ocurre en la semana que graba Morel, sino que consistiría en una emulación (es decir, "la simulación absolutamente precisa de

y grama-escritura: "Escritura Total”. La holografía proporciona una herramienta para registrar, medir y almacenar información, cuya peculiaridad consiste en que cada uno de sus fragmentos contiene la imagen entera.

8 Marvin Minsky, considerado uno de los gurús cibernéticos con mayor repercusión en el pensamiento cibercultural (http://web.media.mit.edu/ minsky/), es uno de los pioneros en el campo de la inteligencia artificial en el MIT (Instituto Tecnológico de Massachusetts). Hans Moravec es especialista en robótica e inteligencia artificial y uno de los exponentes de la filosofía transhumanista (http://www.frc.ri.cmu. edu/ hpm/).

9 Otros científicos, como Michael Shermer o George Ellis, consideran pseudocientíficos los postulados de Tippler.

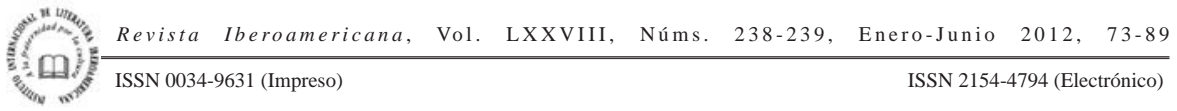


otro objeto" (Tipler 271), y esto nos lleva de nuevo a otros referentes literarios que ya mostraron que ni siquiera la ficción podía soportar la emulación, tal y como ocurre en la "Parábola del palacio", en "Del rigor en la ciencia” y en “Tlön, Uqbar, Orbis Tertius”, de Jorge Luis Borges.

La emulación, según el físico, permite a estos avatares evolucionar igual que sus entes reales y, al contrario que en La invención de Morel, estas simulaciones sí que pueden pensar y relacionarse con su entorno. Lo curioso de esta teoría cientifantástica es que los avatares no saben que están dentro de un ordenador, ni que son una emulación, y esto nos recuerda inevitablemente a la novela de Daniel Galouye Simulacron-3 (1964) y su versión cinematográfica Nivel 13, de Josef Rusnak (1999). En "Otro punto de vista” Bioy sitúa al narrador en la sala de un cinematógrafo para comprender "que no importa lo que nos pase, porque no somos reales, sino un entretenimiento para los dioses, de la misma manera que los personajes de los films lo son para nosotros” (Una magia 133). En la teoría de Tipler una máquina virtual genera una realidad virtual en la que conviven seres emulados que bien podrían denominarse sombras simuelectrónicas que a su vez pueden generar toda una mise en abyme que el científico denomina niveles de implementación. Podríamos comparar con la jerarquía numérica que utilizan en Simulacron-3 para delimitar los diversos tipos de virtualidades que aparecen en el texto. En La invención de Morel la ficción virtual genera una suerte de realidad virtual que funciona como distintos niveles diegéticos en la narración:

La novela de Adolfo Bioy Casares, bajo la perspectiva crítica del hipertexto, puede ser abordada como posible antecedente de las obras que utilizan recursos propios de la cibernética en el montaje de su matriz textual y [...] se convierte en muestra de la metaficción virtual. En ella, existen diferentes niveles de narración; el primer plano pertenece al organizador textual del diario dejado por el prófugo en la isla, donde se había escondido; un segundo plano narrativo se encuentra en los papeles que narran la historia del protagonista, mise en abyme de la primera narración, generadora a su vez de la mise en abyme virtual o mundo virtual proyectado por las máquinas de Morel a fin de aprehender la realidad por toda la eternidad. (Carrera 54)

En este caso, el desdoblamiento diegético en diversas virtualidades ficcionales del texto es análogo a los niveles de implementación descritos por Frank Tipler. También las reproducciones de Clemente Palma evolucionan y pueden interactuar con su entorno, y, como las unidades reaccionales de Galouye, se resisten a su no-existencia basándose en el cogito ergo sum. En estas cajas rusas de virtualidades ficcionales, textuales y reales, las imagocriaturas le hacen cuestionarse a su pateringeniero la realidad de su propia existencia: “¿Cómo sabes tú que la más real de las realidades, no daría un resultado subjetivo, si se la sometiera a un análisis total? Nadie puede demostrar su existencia, ¿no es cierto?” (Galouye 152). Pero, ¿existe realmente el protagonista de La invención

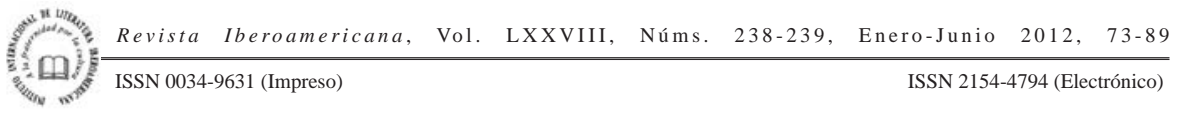


de Morel? El editor del diario encontrado duda constantemente de su testimonio y las indicaciones sobre el estado anímico del protagonista, la ingestión de alucinógenos, la confusión entre el sueño y la vigilia, o la imaginación característica del escritor -como se identifica el fugitivo-, pueden haber virtualizado los hechos de tal manera que lo acontecido tan sólo sucediera en la mente de esta nueva versión robinsoniana.

Podríamos sintetizar como moraleja de las fórmulas matemáticas de Frank Tipler que vivimos en una emulación; que no sabemos si nosotros somos los emulados, y que la inmortalidad la conseguimos gracias a un superordenador que todavía no tenemos la capacidad de inventar, pero que albergará nuestras mentes en una realidad virtual revisitando de nuevo la caverna de Platón y el mundo de Matrix:

¿No debe llamarse vida lo que puede estar latente en un disco, lo que se revela si funciona la máquina del fonógrafo, si yo muevo una llave? ¿Insistiré en que todas las vidas, como los mandarines chinos, dependen de botones que seres desconocidos pueden apretar? Y ustedes mismos, cuántas veces habrán interrogado el destino de los hombres, habrán movido las viejas preguntas. ¿A dónde vamos? ¿En dónde yacemos, como en un disco músicas inauditas, hasta que Dios nos manda nacer? ¿No perciben un paralelismo entre los destinos de los hombres y de las imágenes? (La invención 157-58)

La descripción del mecanismo físico gracias al cual tiene lugar la resurrección universal de Frank Tipler puede resultar del todo excéntrica, pero lo cierto es que nos ayuda a decodificar el universo ficcional de La invención de Morel, ya que tanto el científico como el protagonista y Faustine están inmersos en esa pseudo-realidad virtual inmortal dejando atrás sus corruptibles cuerpos, emulando al protagonista de la película El cortador de césped (Brett Leonard, 1992) cuando se fusiona con la Red. Morel es consciente de que sus reproducciones son o están vivas y que por eso necesita emisores vivos, pero también llega a decir que no crea vida, por lo tanto sólo la transforma. Frank Tipler afirma que existe la vida tras la muerte debido a una inteligencia artificial que denomina "Punto Omega" recogiendo el trabajo del jesuita francés Pierre Teilhard de Chardin (1881-1955). Las simulaciones informáticas de los seres humanos serán la realidad virtual que Tipler denomina resurrección de los muertos, tal y como concibe Morel su universo holográfico. El físico y matemático estadounidense muestra su desacuerdo con el Kant que en La crítica de la razón pura afirma que la ciencia jamás encontrará respuesta a tres cuestiones centrales de la metafísica: Dios, la Libertad y la Inmortalidad (39-40). Tipler “demuestra” científicamente la existencia de Dios y de la Inmortalidad sin apelar a lo sobrenatural, sino considerando el funcionamiento del organismo humano como el de un sistema informático. Y el protagonista de nuestra isla considera que:

Revista Iberoamericana, Vol. LXXVIII, Núms. 238-239,
ISSN 0034-9631 (Impreso) 
[...] teniendo este aparato, conviene inventar otro, que permita averiguar si las imágenes sienten y piensan (o, por lo menos, si tienen los pensamientos y las sensaciones que pasaron por los originales durante la exposición) [...]. El aparato, muy parecido al actual, estará dirigido a los pensamientos y sensaciones del emisor; a cualquier distancia de Faustine, podremos tener sus pensamientos y sensaciones, visuales, auditivas, táctiles, olfativas, gustativas. (166)

¿Qué tipo de inmortalidad proponen estas ficciones tanto científicas como literarias? Los inmortales, ya sean de material biológico, foto(fantasma)fotográfico, virtual o digital, siempre deben pagar un precio, como los habitantes de Luggnagg en Los viajes de Gulliver o las pseudoconciencias atrapadas en la máquina de Mor(t)el.

LA VIRTUALIDAD MOR(T)EL

Para discernir teóricamente los campos semánticos entre los quenavegaremos durante este viaje textual, utilizaremos la terminología de Antonio Rodríguez de las Heras sobre la distinción entre espacio virtual, espacio digital, espacio real y sus características (“Espacio digital” 63). El espacio virtual es aquel generado por la actividad cerebral del ser humano. Es el espacio entre el que transitamos cuando imaginamos, cuando soñamos, cuando nos relacionamos con el más allá, cuando contemplamos un cuadro o abrimos un libro. Cuando realizamos estas actividades navegamos entre los conceptos de nuestras abstracciones cognitivas, vemos imágenes y percibimos las sensaciones de lo acontecido. El espacio digital es un espacio virtual, pero en este caso creado por la actividad tecnológica del hombre. Y el espacio real o natural es en el que vivimos y nos movemos habitualmente. La ficción es uno de los espacios virtuales más transitados por la historia de la humanidad, y Don Quijote el paradigma de la relación entre una realidad forjada de papel y palabras y la de su entorno natural. Wodaski comenta que "durante siglos, los libros han sido la vanguardia en materia de realidad artificial. Piénsese únicamente que al leer las palabras dispuestas en la página, la mente colma los vacíos con imágenes y emociones -e incluso es capaz de suscitar reacciones físicas" (citado por Ryan 110). El espacio virtual se rige por unas propiedades espacio-temporales distintas al espacio real, ya que cuando recordamos algo nos trasladamos en el tiempo o cuando leemos una novela nos sumergimos en un entorno artificial generado por las propiedades semánticas de las palabras. El espacio digital, generado por las nuevas tecnologías informáticas, también está sometido a unas peculiares características que podemos encontrar en la máquina virtual de Morel.

Antonio Rodríguez de las Heras apunta que una de las principales funciones de los espacios virtuales ha sido la de funcionar como una memoria exenta. Desde el libro códice a los diagramas de Ramón Llull y el Memex de Vannevar Bush se han logrado grandes avances en cuanto a los "Medios de alcance y Medios de alcance y

\footnotetext{
Revista Iberoamericana, Vol. LXXVIII, Núms. 238-239, Enero-Junio 2012, 73-89 ISSN 0034-9631 (Impreso) 
retención. La radiotelefonía, la televisión, el teléfono, son, exclusivamente, de alcance; el cinematógrafo, la fotografía, el fonógrafo -verdaderos archivos- son de alcance y retención” (La invención 163). Como la tecnología generada por Morel se encuentra únicamente en el interior de los discos de su máquina en la isla, no cumple con una de las características del espacio digital como la ubicuidad. Paul Virilio considera que la cronopolítica es la que rige el mundo y que las nuevas tecnologías informáticas han mutado el concepto de velocidad haciendo desaparecer las distancias y "hoy en día hemos puesto en práctica los tres atributos de lo divino: la ubicuidad, la instantaneidad y la inmediatez; la visión total y el poder total” (18). Cualquier elemento que introducimos en el espacio digital se hace presente en cualquier punto de la esfera digital y las imágenes de Morel, si no fueran analógicas y estuvieran aisladas, podrían proyectarse simultáneamente en diversos puntos del universo. En el espacio virtual, generado por las nuevas tecnologías, no necesitamos la coincidencia espacio-temporal inherente al espacio real, ya que los objetos pueden funcionar de un modo deslocalizado, sin que los componentes de un mismo objeto se encuentren en el mismo sitio y en el mismo instante (Rodríguez de las Heras, "Espacio digital” 64). La máquina mor(t)eliana tiene receptores y grabadores que captan individualmente cada uno de los elementos del sujeto filmado para proyectarlos de modo simultáneo:

Si abren el receptor de ondas olfativas, sentirán el perfume de las diamelas que hay en el pecho de Madeleine, sin verla. Abriendo el sector de ondas táctiles, podrán acariciar su cabellera, suave e invisible, y aprender, como ciegos, a conocerlas con las manos. Pero si abren todo el juego de receptores, aparece Madeleine, completa, reproducida, idéntica. (156)

Otra de las características de estos entornos virtuales es su plasticidad. Rodríguez de las Heras define como blando este espacio moldeable que podemos transformar en tiempo real sin dejar rastro. El fugitivo-protagonista ocupa el lugar de Morel en el holofilm sin que sea perceptible para un recién llegado a la isla: "Representé bien: un espectador desprevenido puede imaginar que no soy un intruso. Esto es el resultado natural de una laboriosa preparación [...] Cambié los discos; las máquinas proyectarán la nueva semana, eternamente" (183-85).

"Realidad virtual" se ha convertido en un célebre oxímoron cuya combinatoria sintagmática se la debemos a Jaron Lanier. ${ }^{10}$ La realidad virtual es un entorno sintético,

${ }_{10}$ Jaron Lanier es uno de los personajes más relevantes en el desarrollo de la tecnología de realidad virtual y también uno de los mas controvertidos. Acuñó el término Virtual Reality a principios de los ochenta, y fundó la empresa VPL Research Inc. (1985) -junto a Thomas Zimmerman-, empresa con la que comercializó el DataGlove, el Eyephone y el AudioSphere. Entre sus proezas en el campo de la simulación se encuentran la creación del primer entorno de realidad virtual en el que podían participar varios cibernautas -RB2 (Reality Built for Two)- y el haber acuñado el término comunicación postsimbólica

$\begin{array}{lllll}\text { ISSN 0034-9631 (Impreso) } & \text { ISSN 2154-4794 (Electrónico) }\end{array}$ 
generado por gráficos computacionales, con el que tenemos la capacidad de interactuar y sentirnos inmersos de un modo polisensorial. La simulación descrita por Adolfo Bioy Casares muestra la meta de una tecnología que todavía hoy se encuentra en sus primeras fases de gestación. El mundo icónico de Platón se asemeja al entorno de comunicación postsimbólica definida por Jaron Lanier como un intercambio de imágenes y sonido para las comunicaciones del futuro a través de la red y que los hermanos Wachowski dejaron entrever en su distópica trilogía Matrix. La realidad virtual nos sumerge en un entorno digital en el que las imágenes son el medio de comunicación, el lugar habitado y las herramientas -íconos-a través de los que nos manejamos. Si tuviéramos que trazar una genealogía ${ }^{11}$ de la realidad virtual comprobaríamos cómo no es más que el resultado de un proceso antropológico iniciado con las pinturas en relieve de las cavernas, hasta la mímesis clásica retratada por Plinio el Viejo, pasando por la cámara oscura, el Ars Magna de Ramón Llull y la perspectiva geométrica introducida en el Renacimiento. Román Gubern considera que "la RV culmina el ideal ilusionista de la perspectiva geométrica [...], añade a la matemática, la geometría y la óptica renacentistas la aportación decisiva de la microelectrónica y de la informática” (162). También contribuyeron en la generación de estos espacios tridimensionales sintéticos la linterna mágica, los robots matemáticos de Blaise Pascal y Gottfried Wilhelm Leibniz, la estereoscopia y el Ingenio Diferencial y Analítico de Ada Lovelace y Charles Babbage -que retrataron William Gibson y Sterling en su novela steampunk, La máquina diferencial (1990)-. Fruto de esta tradición tecno-conceptual y haciendo uso de la tecnología fotográfica, fonográfica y cinematográfica, Morel genera un entorno de imágenes inmersivo en el que cualquier sujeto puede penetrar sin necesidad de ropa computarizada y percibir todos los sentidos. En el sigo xxi todavía no existe la tecnología de realidad virtual imaginada por Ivan Shuterland, y por ahora la generación sinestésica de artificialidades en relieve está vedada únicamente al espacio de la pleonástica virtualidad ficcional, aunque actualmente Marina Bloj, del Departamento de Optometría de la Universidad de Bradford, trabaja en la creación de un visiocasco capaz de emular los cinco sentidos.

para referirse a toda comunicación en la que se intercambian sonido e imágenes a través de las nuevas tecnologías: "There are a few special things about Virtual Reality to keep in mind, the things that make it important. One is that it's a reality in which anything can be possible, provided it's part of the external world. It's a world without limitation, a world as unlimited as dreams. It's also a world that's shared, like the physical world. It's as shared and as objectively real as the physical world is, no more, no less. Exactly how shared or real that is, is open to question, but whatever the physical world has Virtual Reality has as well. The thing that's remarkably beautiful to me about Virtual Reality is that you can make up reality in Virtual Reality and share it with other people. It's like having a collaborative lucid dream. It's like having shared hallucinations, except that you can compose them like works of art; you can compose the external world in any way at all as an act of communication” (en línea).

11 Sobre la genealogía de la realidad virtual, desde una perspectiva humanística, remitimos a los trabajos de Tomás Maldonado Lo real y lo virtual y de Román Gubern Del bisonte a la realidad virtual.

\begin{tabular}{l} 
Revista Iberoamericana, Vol. LXXVIII, Núms. 238-239, Enero-Junio 2012, $73-89$ \\
\hline ISSN 0034-9631 (Impreso)
\end{tabular} 
GAME OVER

Cuando leemos una novela participamos en una simulación textual donde no está en juego la unidad del texto, sino la construcción del yo, porque el texto nos sirve “como interfaz con nosotros mismos” (Lévy 36). La literatura y la realidad virtual nos proporcionan sensaciones a través de la imaginación y del lenguaje, por lo que la analogía entre ambas simulaciones es natural, ya que “[...] la literatura puede representar el espectro entero de la experiencia humana. La capacidad del lenguaje para sustituir a todos los canales de la sensación es lo que justifica la comparación de la literatura con un modo de comunicación multimedia como el de la realidad virtual” (Ryan 112). $\mathrm{El}$ lector puede experimentar consigo mismo a través de los reflejos que emanan los distintos personajes de un relato literario, igual que puede hacerlo con los diversos avatares adquiridos en un metaverso. Los MUD $^{12}$ son una realidad virtual basada en el texto. En lugar de utilizar ropa computarizada como interfaz, nos sumergimos en las sensaciones del ciberespacio a través de las palabras, construyendo los personajes y la realidad del mundo virtual en tiempo real. El proceso de ficcionalización sería lo que para Pierre Lévy supone el proceso de virtualización: consistiría en un movimiento de "convertirse en otro" que afecta a la información, a la computación, a los cuerpos, la economía y el ejercicio de la inteligencia. Para Lévy la virtualización es uno de los principales vectores de la creación de realidad y Wolfgang Iser considera que "si el yo íntimo de la persona es el punto de encuentro de sus múltiples papeles, las ficciones literarias muestran a los seres humanos como ese algo que ellos se hacen ser y como que ellos entienden que son” (57). Sherry Turkle, en La vida en la pantalla, considera los MUD como laboratorios para experimentar con la identidad:

Los juegos de simulación no son objetos para pensar sobre el mundo real, sino para provocar nuestra reflexión sobre cómo el mundo real se ha convertido a sí mismo en un juego de simulación. [...] Por tanto utilizamos las simulaciones para pensar a través de la pregunta ¿qué es real? ¿Qué queremos que cuente como real? ¿En qué grado queremos tomar las simulaciones por realidad? ¿Cómo mantener la visión de que existe una realidad distinta a la de la simulación? (93)

Las proyecciones de Mor(t)el se distribuyen por el espacio y el científico presume que ningún testigo admitirá que son imágenes, y que nadie creerá en la perfección de su invento ya que sería más sencillo pensar que ha contratado a un grupo de actores. El protagonista no sabe si está soñando, si él está muerto o están muertas las personas que ve por la isla. Se cuestiona estar en un manicomio o que todo sea un juego macabro

${ }_{12}$ Los MUD (Multi User Dungeon) son espacios para múltiples usuarios en los que cualquier usuario puede interpretar un papel en el juego de rol digital a través del texto.

\footnotetext{
Revista Iberoamericana, Vol. LXXVIII, Núms. 238-239, Enero-Junio 2012, 73-89 ISSN 0034-9631 (Impreso) IISN 2154-4794 (Electrónico)
} 
cuya finalidad es la de hacerle prisionero. Pero a pesar de todo decide entrar a formar parte activa de la simulación textual de Bioy Casares y de la realidad virtual generada por el aparato de Morel. Al margen de la explicitación de la metáfora cinematográfica en el texto podemos analizar la inmersión del protagonista como si entrara a formar parte de una suerte de MUD de aventuras. Bajo el avatar de un náufrago fugitivo jugará durante toda la novela intentando vencer al master del juego (Morel). Su objetivo principal será encontrar el tesoro-máquina necesario para dominar el juego y conseguir a Faustine (mujer digital). Hasta llegar al objetivo, el fugitivo tendrá que pasar penurias y aprender a utilizar el espacio físico en el que se desarrollará la historia: una isla. Al entrar en el juego va ganando puntos a través de la experiencia, eliminando enemigos y encontrando ciertos tesoros. Los puntos de experiencia se traducen en incremento de poder, y en la novela de Bioy Casares la experiencia del protagonista en la isla, junto al aprendizaje acerca del funcionamiento de las máquinas y el estudio de las costumbre de los hologramas, harán del fugitivo el master del juego. De hecho, será el conocimiento de la tecnología de la isla lo que le hará poderoso. La soledad y el ostracismo hacen que el protagonista se introduzca en la simulación recreando una especie de relación social con los habitantes de la isla y una especie de historia de amor con Faustine.

La etimología de los entornos virtuales surge de nuestra interacción con ellos. Sólo podemos hablar de espacio virtual si podemos introducirnos y salir de él en tiempo escogido. Antonio Rodríguez de las Heras considera que una de las principales características del espacio virtual es su contigüidad con el espacio real y sintetiza esta propiedad en la bella metáfora de la playa:

Nuestro mundo de los sentidos entra en contacto con nuestros mundos virtuales y da como resultado lo que llamamos realidad. Por un lado está la tierra firme de los sentidos y por el otro los mares de las creaciones virtuales, cuando entran en contacto aparece la playa de la realidad, que es continente y mar a la vez. La playa es tierra y agua en un incesante flujo y reflujo. Si nos separamos de la playa y nos vamos tierra adentro, entramos en el estado vegetativo. Si, por el contrario nos metemos en el mar, nos ahogamos en la ensoñación patológica. ("Espacio digital” 65)

El tránsito entre los mundos virtuales puede atraparnos en la ensoñación patológica como a Don Quijote o al protagonista de Bioy Casares, pero también debemos huir del estado vegetativo a través del “iVive e inventa!” que postula Beckett en Malone -y que podríamos traducir como 'vive y ficcionaliza’ o ‘virtualiza’-. Lo ideal sería poder transitar por esa orilla liminar en la que convivimos entre virtualidades y realidades -cada vez mas virtualizadas-.

El simulacro vital mecanizado que nos propone el escritor argentino aparenta un metaverso en el que nuestro fugitivo protagonista primero es espectador y luego actor, en la simulación amorosa generada por Morel. Se introduce en la máquina,

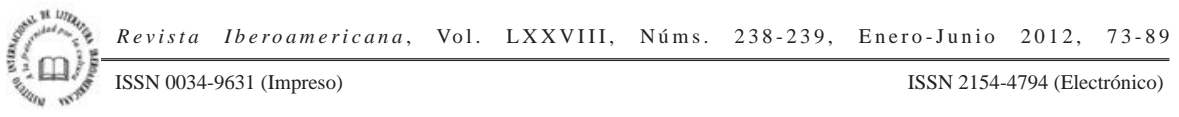


como Alicia a través del espejo, convirtiéndose en intérprete y guionista de su propia historia, suicidándose en el texto para vivir eternamente en la imagen de la realidad virtual moreliana. La duplicación diegética del texto nos sitúa en diversos niveles de virtualidad que muestran una Simulación Sentimental-1 (SS-1) de Morel con Faustine y la SS-2 del protagonista con la imagen de Faustine. El fugitivo de la virtus-isla no sabe nada sobre esta mujer, como muchos ciberusuarios no conocen la realidad de los avatares con los que chatean o se relacionan en Second Life, pero cuando está a punto de morir recuerda a una mujer de carne y hueso que le ayudó siempre: "mientras mire a Faustine no te olvidaré" (86). Este dato es trascendental ya que Faustine se convierte en el revenant de Elisa y podemos preguntarnos si el protagonista quiso de verdad a Faustine en algún momento o simplemente representaba, simulaba, aquello que él amaba. Aunque adore la imagen de Faustine o el recuerdo de Elisa, lo que realmente le impulsa a actuar es un referente humano y real que no puede alcanzar materialmente y por eso busca su análogo inmaterial, holográfico o virtual. ¿No es esta motivación la que empuja a muchos individuos de nuestra sociedad a encerrarse en sus "islas" y actuar de este modo en la red? “¿Psicoterapia o adicción?: Para algunos usuarios el MUD ha servido de terapia, pero otros lo han utilizado como una adicción a perder el tiempo para no tener que sentir las cosas, pasar el tiempo aparcando los problemas” (Turkle 249). Hemos pasado de la Caverna de P(latón)iedra a la Caverna Telemática en la que los peligros de Pigmalión pueden seducirnos hasta transformarnos en zombis cibernéticos o cyborgs con conciencia de clase. Tal y como publicaba la portada de la revista Time (2006), "Yes, you. You control the Information Age. Welcome to your World", bienvenido al desierto de lo real.

\section{BiBLIOGRAFÍA}

Alonso, Andoni e Iñaki Arzoz. La nueva ciudad de Dios. Un juego cibercultural sobre el tecno-hermetismo. Madrid: Siruela, 2002.

Baudrillard, Jean. Cultura y simulacro. Barcelona: Editorial Kairós, 2001.

Bioy Casares, Adolfo. La invención de Morel.1940. Madrid: Cátedra, 2001. Una magia modesta. Barcelona: Tusquets, 1998.

Burch, Noël. El tragaluz del infinito. Madrid: Cátedra, 1999.

Burdea, Grigore y Philippe Coiffet. Tecnologías de la Realidad Virtual. Barcelona: Paidós, 1996.

Cano, Luis C. Intermitente recurrencia. La ciencia ficción y el canon literario hispanoamericano. Buenos Aires: Corregidor, 2006.

Carrera, Liduvina. La metaficción virtual. Caracas: Universidad Católica Andrés Bello, 2001.

Clute, John y Peter Nichols. The Encyclopedia of Science Fiction. Londres: Orbit, 1993.

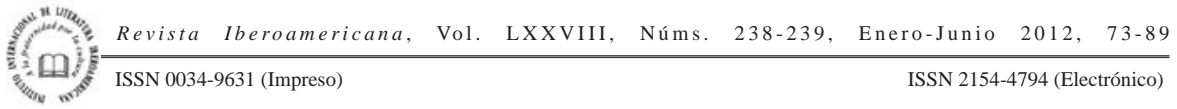


Galouye, Daniel F. Simulacron-3. Málaga: Editorial Ferma, 1967.

Gardner, Martin. ¿Tenían ombligo Adán y Eva? La falsedad de la pseudociencia al descubierto. Barcelona: Debate, 2001.

Gibson, William. Neuromante. Barcelona: Minotauro, 1997.

Gubern, Román. El bisonte y la realidad virtual. La escena y el laberinto. Barcelona: Anagrama, 1996.

Holmberg, Eduardo L. Horacio Kaliban o los autómatas. Buenos Aires: Imprenta El Álbum del Hogar, 1879.

Iser, Wolfgang. “La ficcionalización: dimensión antropológica de las ficciones literarias”. Teorías de la ficción literaria. Antonio Garrido Domínguez, editor. Madrid: Arco/ Libros, 1997.

Lanier, Jaron. “A Vintage Virtual Reality Interview”. 1988. <http://www.jaronlanier. com/vrint.html>. 15 ago. 2009.

Lévy, Pierre. ¿Qué es lo virtual? Barcelona: Paidós, 1998.

Maldonado, Tomás. Lo real y lo virtual. Barcelona: Gedisa, 1994.

Mirandola, Pico della. "De la dignidad del hombre". 1486. <http://www.ciudadseva. com/textos/otros/pico.htm>. 3 mayo 2008.

Negroponte, Nicholas. El mundo digital. Bilbao: Ediciones B, 1996.

Noble, David. La religión de la tecnología. Barcelona: Paidós, 1999.

Palma, Clemente. XYZ. Lima: Ediciones Perú Actual, 1935.

Quiroga, Horacio. "El vampiro”. Historias futuras. Antología de la ciencia ficción argentina 1935. Adriana Fernández y Edgardo Pígoli, pról. y sel. Buenos Aires: Emecé, 2000.

Ríos, Valeria de los. "Llévese la cámara a la tumba: deseo fotográfico en cuatro cuentos de Lugones”. Revista Iberoamericana LXXIII/221 (2007): 745-58.

Rodríguez de las Heras, Antonio. "Espacio digital. Espacio virtual”. Revista Debats 84 (2004): 63-67.

“Hiperpresentación”. La nueva ciudad de Dios. Un juego cibercultural sobre el tecno-hermetismo. Andoni Alonso e Iñaki Arzoz. Madrid: Siruela, 2001. 13-18.

Ryan, Marie-Laure. “Inmersión o interacción: Realidad virtual y teoría literaria”. Literatura Hipertextual y teoría literaria. María José Vega, eda. Madrid: Marenostrum, 2003.

Stephenson, Neil. Snow crash. Nueva York: Bantam, 1992.

Tipler, Frank J. La física de la inmortalidad. Madrid: Alianza, 2005.

Turkle, Sherry. La vida en la pantalla: construcción de la identidad en la era de Internet. Barcelona: Paidós, 1995.

Virilo, Paul. El cibermundo, la política de lo peor. Madrid: Cátedra, 1999.

Revista Iberoamericana, Vol. LXXVIII, Núms. 238-239, Enero-Junio 2012,
ISSN 0034-9631 (Impreso) 
